\title{
Essentials of Documentation in Interventional Pain Medicine
}

\author{
Laxmaiah Manchikanti, MD
}

Documentation in interventional pain medicine is an important, and, at times, most crucial facet of practice. For physicians, documentation has always meant providing information or evidence on multiple issues, including evaluation and management services, procedural services, billing and coding. With the increasing sophistication and complexity of interventional medical practices, the need to record specific clinical data has grown in importance.

Documentation reflects competency, character and caring of the pain management specialists. The Office of the Inspector General reported overpayments of $\$ 23.3$ billion in 1996, $\$ 20.3$ billion in 1997, $\$ 12.6$ billion in $1998, \$ 13.5$ billion in 1999, $\$ 11.9$ billion in 2000 , and $\$ 12.1$ billion in
2001 in health fraud. Thus, the government has been increasing its efforts to prevent fraud and abuse by reducing the error rate for Medicare-fee-for-service and by improving documentation. Documentation errors have contributed to $70 \%$ to $80 \%$ of the errors.

This review describes various elements of documentation, documentation standards and the government's perspective on documentation, as well as the process of documentation.

Keywords: Interventional pain medicine, documentation, Health Insurance Portability and Accountability Act, Medicare, fraud and abuse
Documentation is to provide evidence or information. For physicians documentation means providing information or evidence on multiple issues, including evaluation and management services, procedural services, billing and coding. If a physician wants to get reimbursed for the services or stay out of fraud and abuse investigations, three important aspects of medical practice are document, document and document. Even though healthcare is not so different from other industries and services, documentation has become an inevitable and even desirable part of medical practice. The entire basis of documentation is control and the dominant role of the government (1). Pauly (2) describes that public policy in health most frequently assumes that the social purposes people correctly ascribe to healthcare can only and obviously be solved by government, with the market possibly supplying services, but in very much a subsidiary role. Stigler (3) initiated a positive theory of regulation based on the plausible assumption that government regulators sometime pursue their own interest and those of the industries they regulate, rather than some vaguely defined public interest. However, these are not

From Pain Management Center of Paducah, Paducah, Kentucky. Dr. Manchikanti is the medical director at the Pain Management Center of Paducah. Address correspondence: Laxmaiah Manchikanti, MD, 2831 Lone Oak Road, Paducah, Kentucky 42003. E-mail: drm@asipp.org unthinking arguments against government. Quite the contrary, it is the recognition of the need for government, and of the power of its actions (2). Assurance of adequate care for those we care about, preventing monopoly pricing, and helping to encourage the flow of good information are topics that come up over and over, and represent tasks in which government has an inevitable role (2). Of these tasks, the assurance of adequate care is the one that most requires government, and which has proved the most stubbornly resistant to solution (2). The physician community believes that even though the public in general and the regulators believe that the provision of healthcare attracts more dedicated and selfless people than the typical commodity, there is always the possibility of providing inadequate care.

President Clinton's healthcare reform proposals of 1993 represented the most far-reaching program of social engineering to be attempted in the United States since the passage of Medicare and Medicaid in 1965 (4). Fortunately, this plan failed. Many people commented that the plan failed because too many people concluded that it wasn't credible. The fundamental fact is that the healthcare reform failed because people don't trust the government to manage their medical care - a business that accounts for one of every $\$ 7$ spent in the United States, and a healing art that touches the lives of almost every citizen (4). However, the Clinton administration didn't stop assault on healthcare at that level. On August 1 and 2, 1996, con- 
gress cleared for the President's signature, the Health Insurance Portability and Accountability Act of 1996, known as the Kennedy-Kassabaum Bill (5). There was very little dissent even in the republican controlled congress. This bill came with a disguise and even the liberal press reaction was favorable. The bill included the sexy title: Portability and Accountability. President Clinton signed the bill into law on August 21, 1996 (5). Unknown until recently, this act contained major provisions of the Clinton Administration's previously rejected 1993 Health Security Act and many other issues regarding to privacy, administrative simplification, fraud and abuse leading to increased focus on documentation. Thus, in today's modern medicine, there has been such an emphasis on the description and definition of what the physician does for and to the patient, which has never been witnessed in the history of the United States. The Kennedy-Kassabaum Health Reform Bill of 1996 provided the Office of the Inspector General (OIG) and the Federal Bureau of Investigation with broad powers and directed them to identify and prosecute healthcare fraud an abuse.

\section{HISTORICAL CONSIDERATIONS}

The role played by documentation has always been a supportive one but a critical one. However, as the practice of medicine has become more sophisticated and complex, the need to record specific clinical data has grown in importance. What began as a simple written mechanism to remind the treating physician involved into a refined system to serve others assisting in patient care, which also has become a complex product. Until early 1970s, no clear standards existed for medical record documentation. In the olden days, medical documentation was not only seen and maintained but was used almost exclusively by physicians in medical staff. It was also considered as the property of the individual physician or provider organization. Thus, it was very unusual to submit patient care information to insurance companies. In contrast, in today's medicine specifically in interventional pain management, any claim submitted for reimbursement must be supported by clear and accurate documentation.

The developments in the mid 1970s, irrevocably affected the role of documentation in medicine. This was fueled by a dramatic nationwide increase in medical malpractice claims and awards, changes in the fledgeling Medicare program during the 70s, emergence of electronic review process in 1980s adding even a newer twist, Medicare Prospective Payment Systems, and finally, documentation for evaluation and management services in the early 1990s.

\section{IMPORTANCE OF DOCUMENTATION}

Documentation reflects competency, character and caring of the pain management specialists (6). However, documentation is not limited only for the physician and provider practices, but also physicians are obligated to document incorrect or incomplete answers from third party payors, including Medicare and Medicaid programs. A

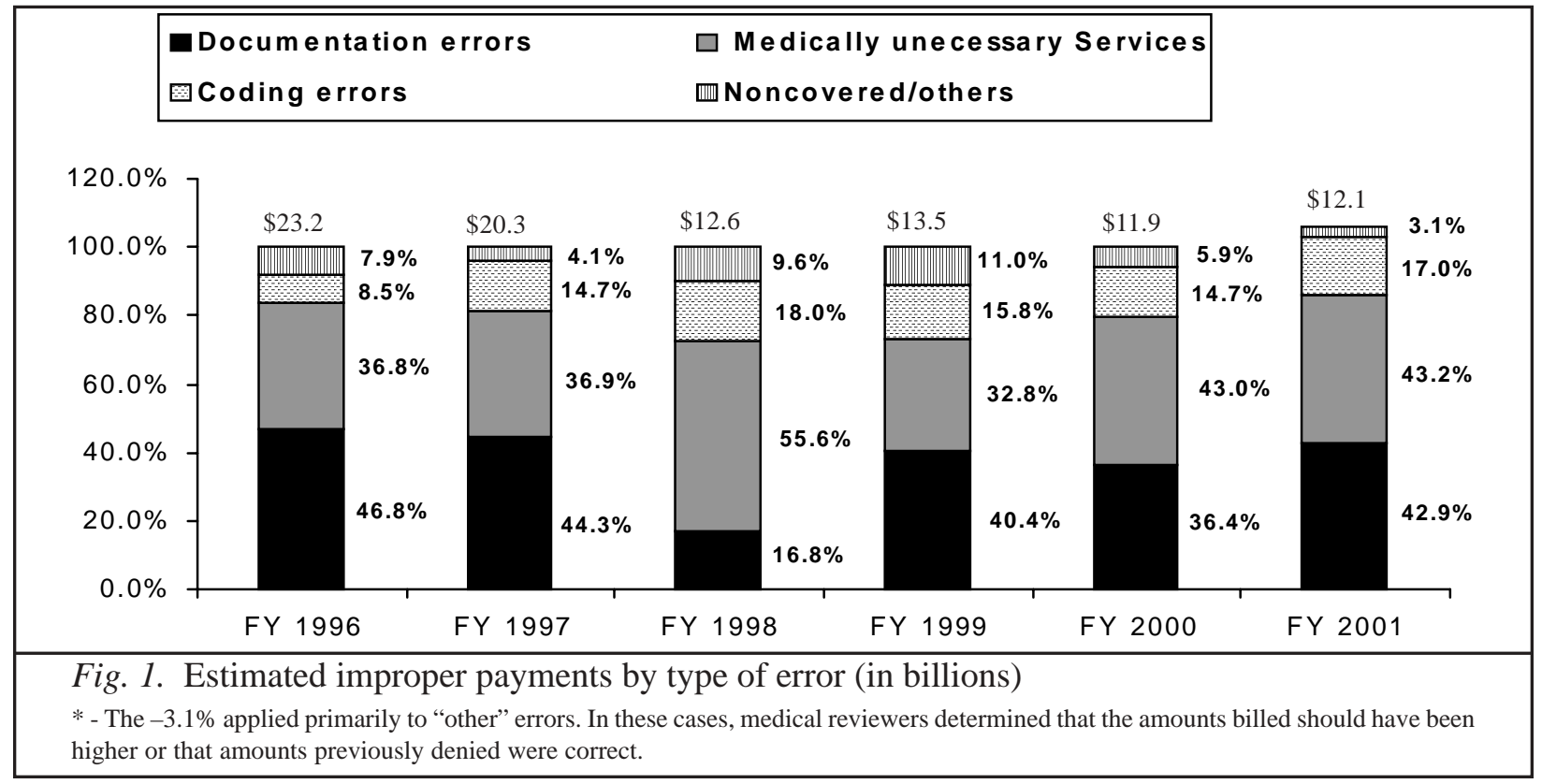




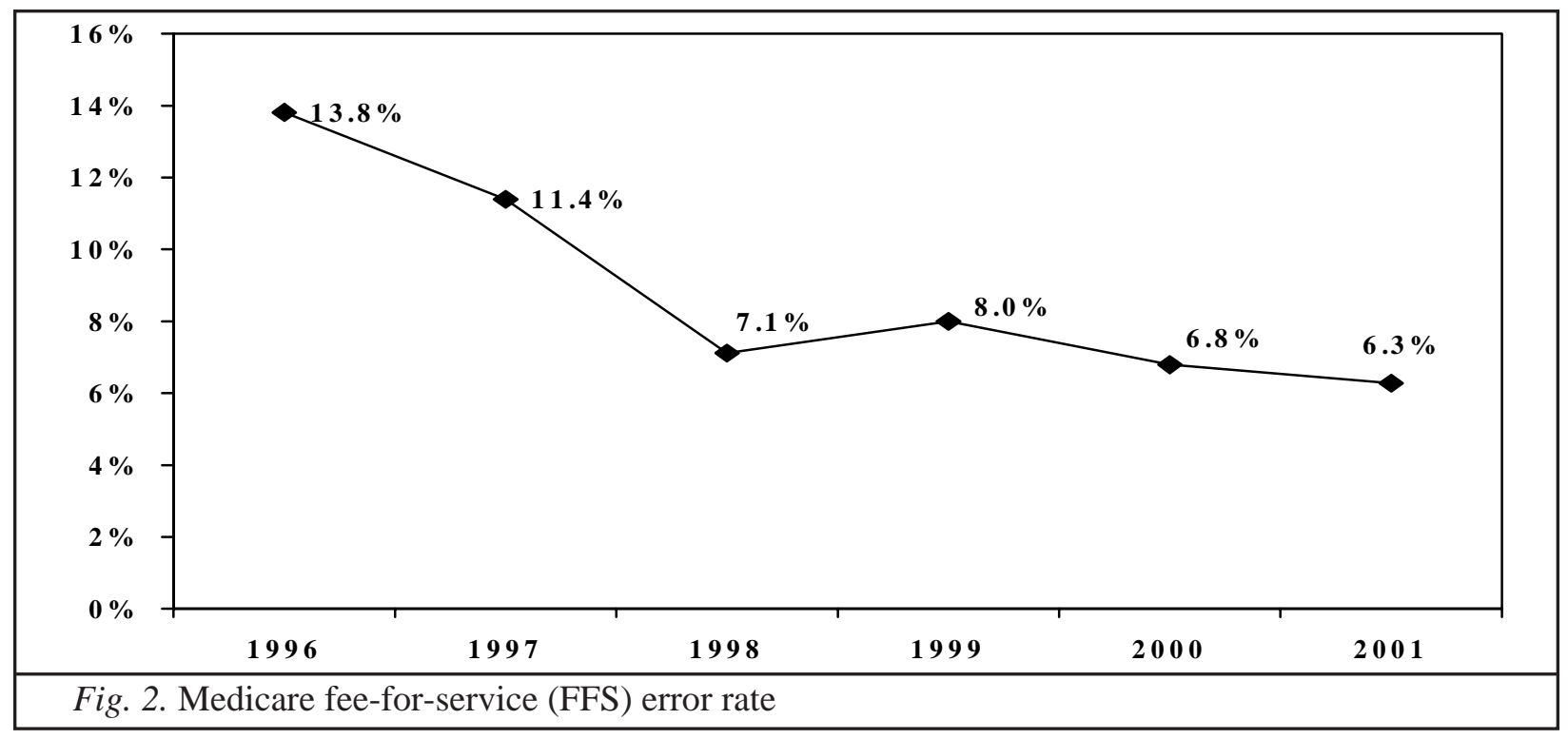

general accounting office study submitted to Ways and Mean Health Subcommittee on September 25, 2001, showed that Medicare carriers were often wrong approximately $85 \%$ of the times and provided incorrect or incomplete answers. The Office of Inspector General reported overpayments of $\$ 23.3$ billion in 1996, \$20.3 billion in $1997, \$ 12.6$ billion in $1998, \$ 13.5$ billion in $1999, \$ 11.9$ billion in 2000, and 12.1 billion in 2001 in health fraud. As shown in Fig. 1, physician overpayments are significant. The government also has shown that increased efforts to prevent fraud and abuse have reduced the Medicare fee-for-service error rates significantly (Fig. 2). In fact, documentation errors were shown to be $70 \%$ and $79 \%$ in 1998 and 1999. The most important causes of the offensive on physician practices with heightened requirements for documentation or increasing healthcare costs, Clinton administration, HIPAA and Balanced Budget Act. Figure 3 shows documentation errors as a percentage of total estimated improper payments.

\section{DEVELOPMENT OF MEDICARE AND MORE}

In June 1883, Bismarck, then chancellor of a newly united Germany, successfully gained the passage of a compulsory health insurance bill covering all factory and mine workers (7). In Great Britain, George, Chancellor of the

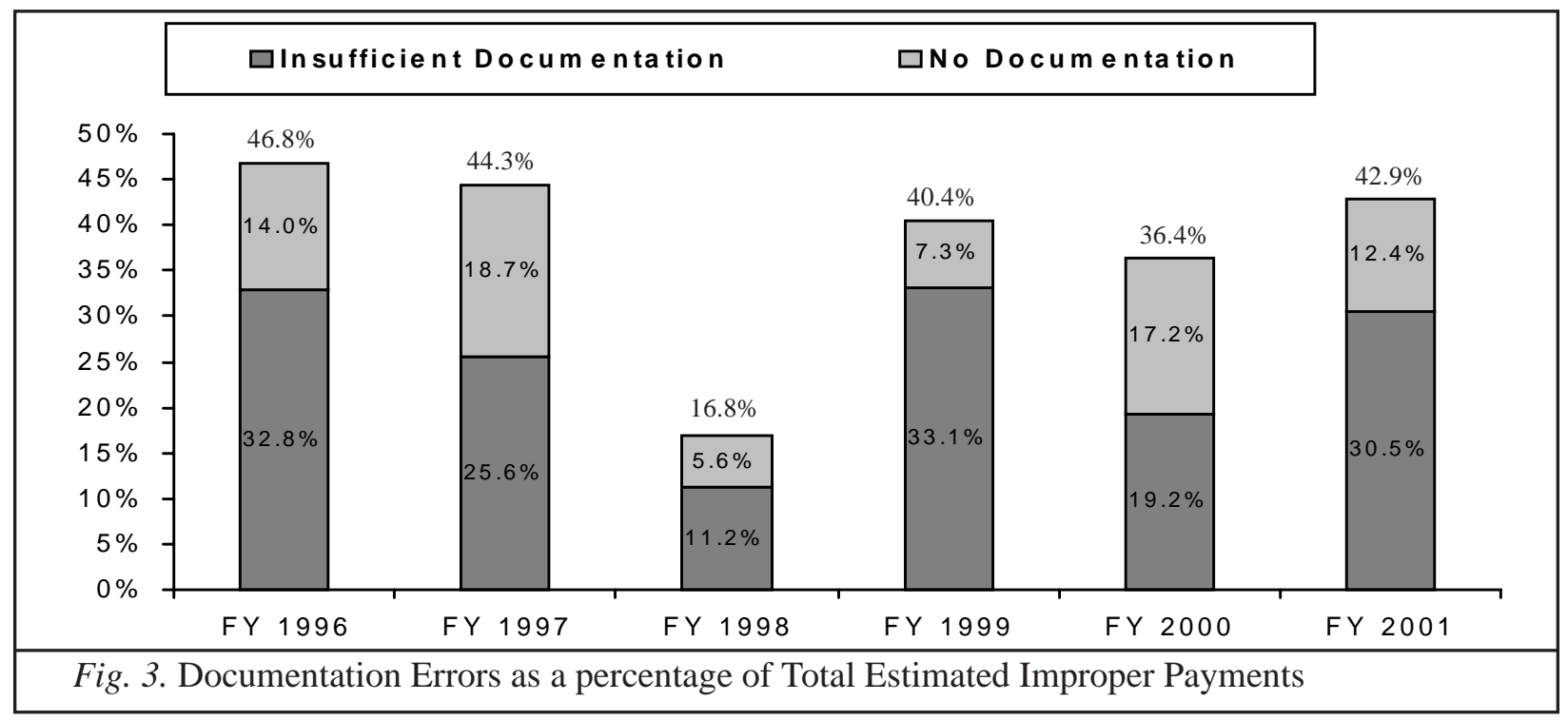


Exchequer, from 1901 until 1914 introduced a national health insurance scheme on the part of the government in 1911, based on Bismarck's success (7). Thus, a compulsory system of health insurance became of subject of American presidential politics. On August 6, 1912, Theodore Roosevelt, as a presidential candidate, called on for a national compulsory healthcare scheme for all industrial workers (8). Following numerous tribulations, in spite of the opposition from AMA, with several presidents and congressional leaders changing their propositions, on July 30, 1965, President Johnson, signed the Medicare bill in the presence of former president, Truman into law in Independence, Missouri. The main provisions of the 1965 legislation were as follows (7):

1. Hospital insurance for all person's over the age of 65 , otherwise entitled to benefits under the Social Security Railroad Retirement Acts, known as Medicare Part A.

2 Supplementary medical insurance for all persons over 65 , eligible for participation in this program on a voluntary basis, without the requirement that they had earlier paid into the Social Security Program, known as Medicare Part B.

3. In addition, the 1965 legislation provided states a number of options regarding their level of participation in Medicaid, ranging from opting out of the program entirely to including all covered services for all eligible classes of persons.

In 1967, the Johnson Administration proposed amendments to the Social Security Program that included extending Medicare benefits to the disabled who were otherwise eligible for cash payments. Perhaps the most significant change to the Medicaid program contained in the 1972 amendments was the repeal of a provision contained in the 1965 legislation that made it mandatory that each state expand its Medicaid program each year until it offered comprehensive coverage for all the medically needy by 1977 (7). In addition, there was also a provision in 1972 legislation which established the Professional Standards Review Organizations, whose function was to assume responsibility for monitoring the costs, degree of utilization, and quality of care of medical services offered under Medicare and Medicaid. In 1974, a reimbursement cap was instituted that limited hospitals from charging more than $120 \%$ of the mean of routine costs in effect in similar facilities, a limit later reduced to $112 \%$. In 1974, a new legislation was enacted whose goal was to reduce the construction of new hospitals. Thus, the National Health Planning and Resource Development Act mandated that Certificate-of-Need (CON) programs be instituted in each of the states to regulate the construction of new healthcare facilities. However, this program was of limited value despite its enormous cost, with little impact on new hospital construction.

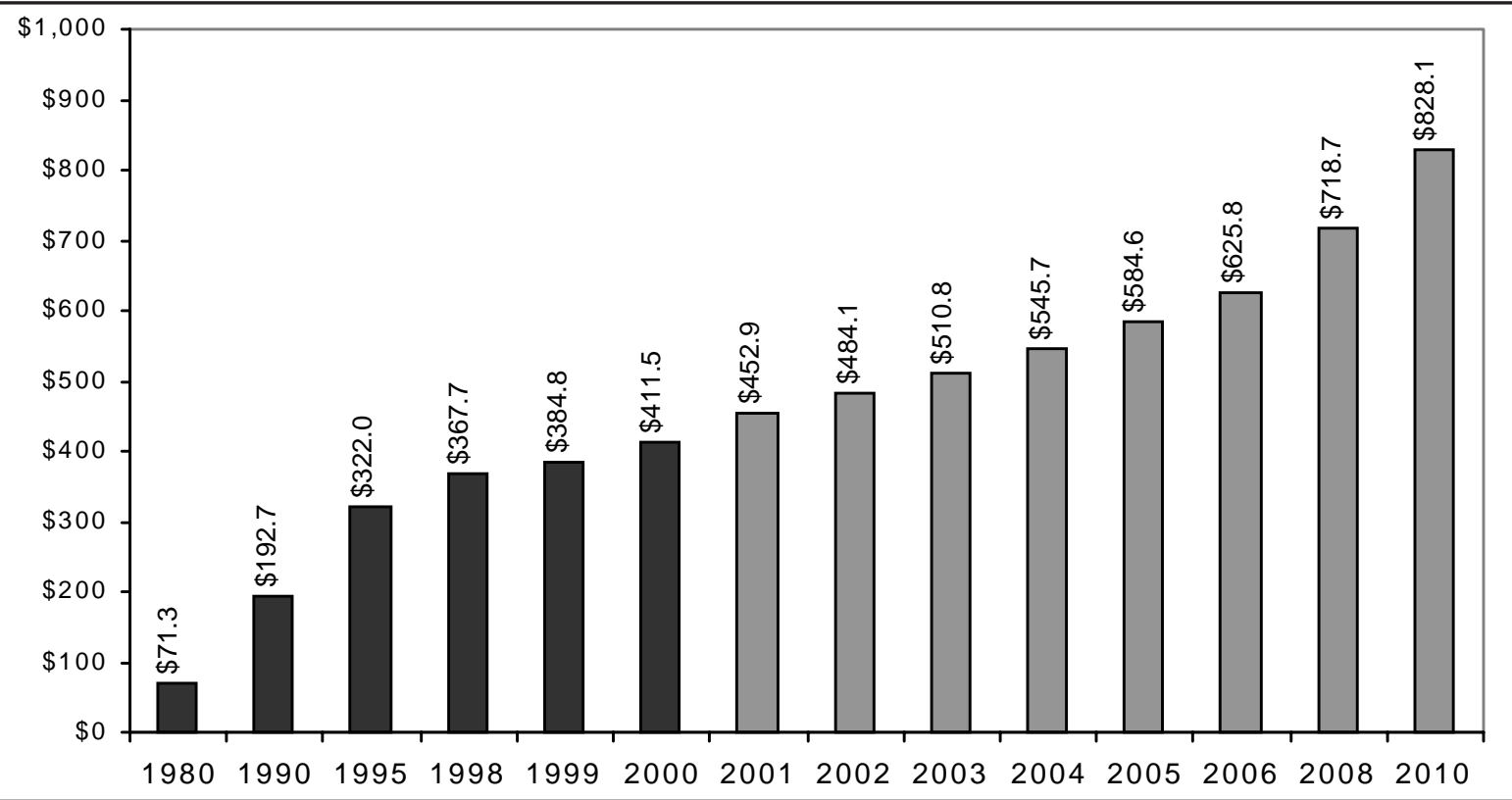

Fig. 4. Government sponsored Health care expenditure on health (Projections were based on the 2000 version of the National Health Expenditures) 
In 1981, Omnibus Budget Reconciliation Act (OBRA) was enacted limiting reimbursements for a large number of inpatient and outpatient services. Subsequently, the Tax Equity and Fiscal Responsibility Act (TEFRA), was enacted in 1982, introducing a flat payment per hospital patient based on the historic average cost of care and instituted a ceiling on increases in hospital revenue. This act also permitted states to require copayments from most Medicaid recipients, altered the terms under which HMOs entered into risk-sharing contracts to make them more attractive and made Medicare the secondary, rather than the primary, insurer in the case of workers under the age of 70 covered by a company health insurance plan. The combined effect of OBRA and TEFRA reforms was to introduce hospital budget caps to Medicare patients. Subsequently, radical changes in payment systems appeared with a prospective payment system (PPS) introduced for hospitals in 1983, at which time hospital payments accounted for more than $68 \%$ of total Medicare expenditures. Subsequently, since physician payments were increasing out of proportion, a physician payment review commission was established in 1986. Prospective payment system for physicians also was implemented starting January 2, 1992 with reaching full implementation by 1996 . Finally, the Outpatient Prospective Payment System was introduced in August 2000 .

\section{HEALTH CARE COSTS}

Increasing healthcare costs has been a problem ever since
Medicare was introduced. It was clear following the first full year of operation of the hospital insurance program that its costs significantly exceeded the estimates put forward by the programs proponents. By 1972, the costs associated with Medicare had increased at such a rate that even the administration and Congress were expressing their concern. It was shown that hospital service charges rose much faster than the consumer price index and additionally faster than the medical care component of that index. Over the course of the first five years of Medicare that ended in 1971, physicians' charges rose 39\%, compared with a $15 \%$ rise in the five years before the advent of Medicare. Further, healthcare expenditures of the elderly that originated in public sources rose more sharply than had been expected prior to Medicare's passage. In the fiscal year 1966, government programs provided $31 \%$ of the total expended on healthcare for the elderly. Just one year later, this proportion had increased to $59 \%$ and Medicare alone accounted for 35 cents of every dollar spent on health services by or for those over the age of 65. As shown in Fig. 4, Government sponsored health care expenditures have increased substantially since its inception in 1965.

Along with Medicare expenditures, national healthcare expenditures also have been increasing. In fact, national health expenditures are projected to total \$2.6 trillion and reach $16.8 \%$ of Gross Domestic Product (GDP) by 2010 after having declined from $13.4 \%$ in 1995 to $13.1 \%$ in 1999. Fig. 5 shows national health expenditures through 1982 to 2010 with actual numbers from 1980 to 2000 and projec-

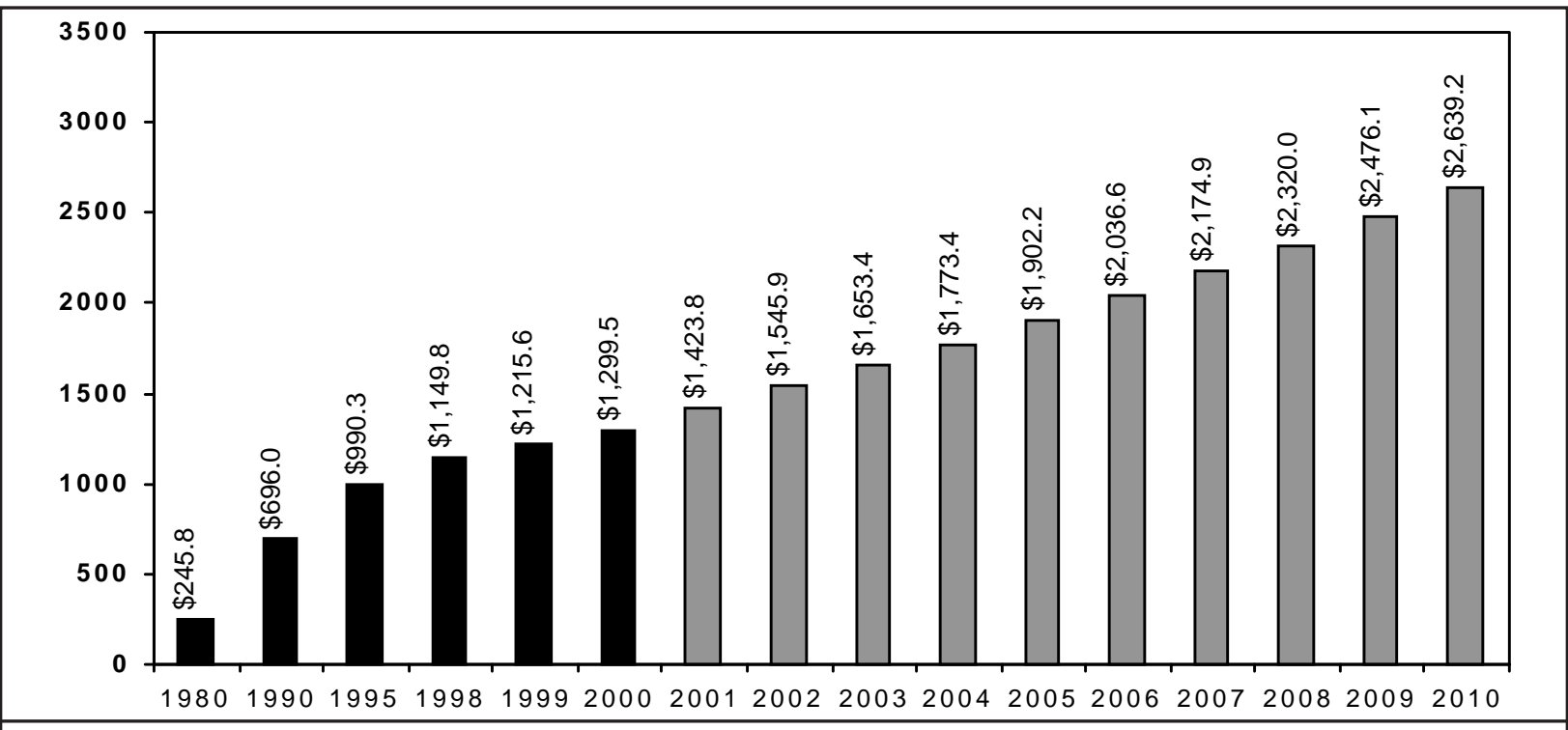

Fig. 5. National Health Expenditures in billions (actual or Projections were based on the 2000 version of the National Health Expenditures) for selected calendar years 1980-2010 


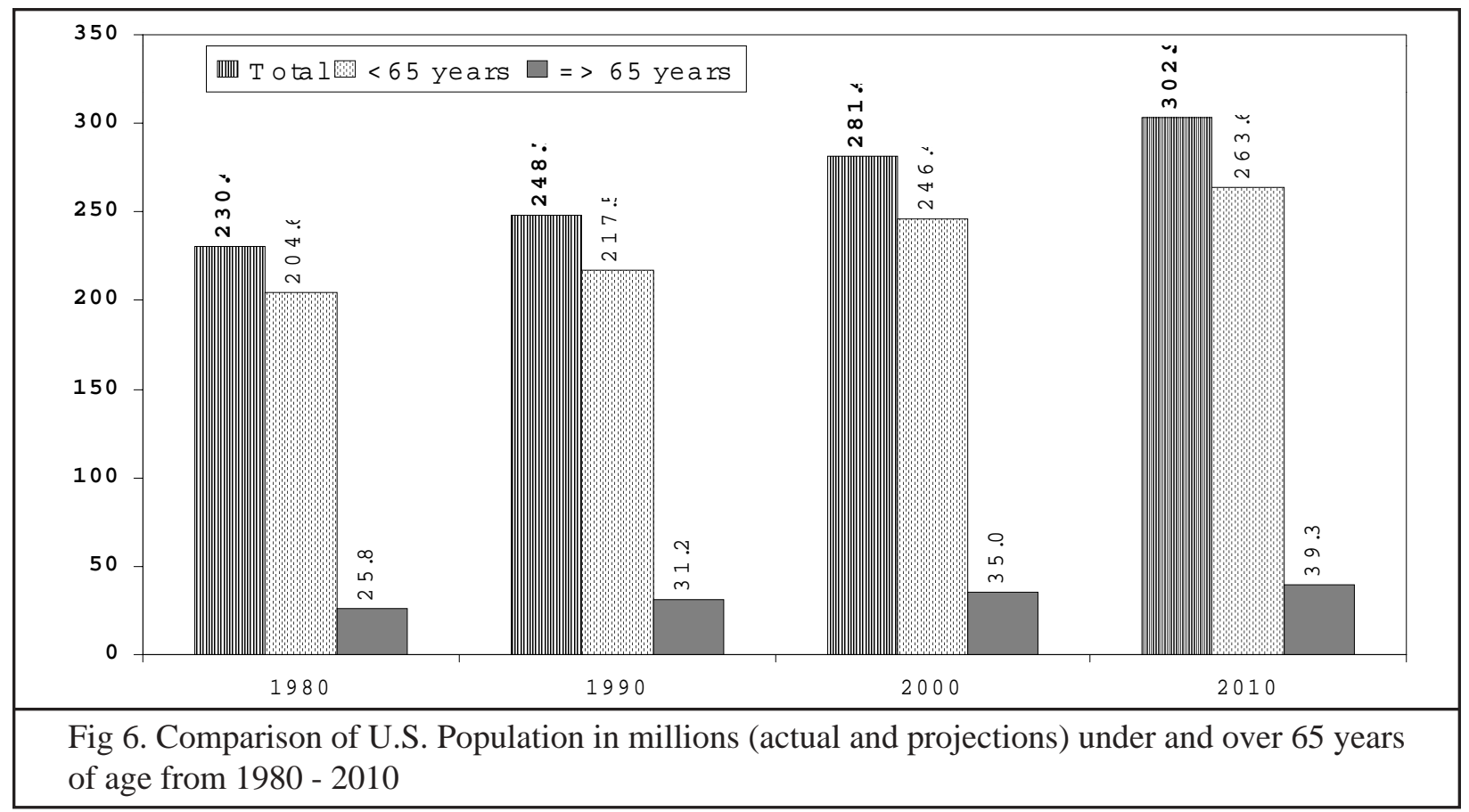

tions (based on the 2000 version of the National Health Expenditure) from 2001 to 2010. Fig. 6 shows US population in millions with age less than 65 years and those 65 years and older. Fig. 7 shows national health expenditures as a percent of gross domestic product, which increased from $8.8 \%$ in 1980 to $13.2 \%$ in 2000 and is expected to increase to $16.8 \%$ in 2010. Fig. 8 shows growth of various sectors in healthcare with substantial increase for prescription drugs compared to all other sectors.

Thus, cost containment was initiated not only in the public sector, but also in the private sector. Managed healthcare

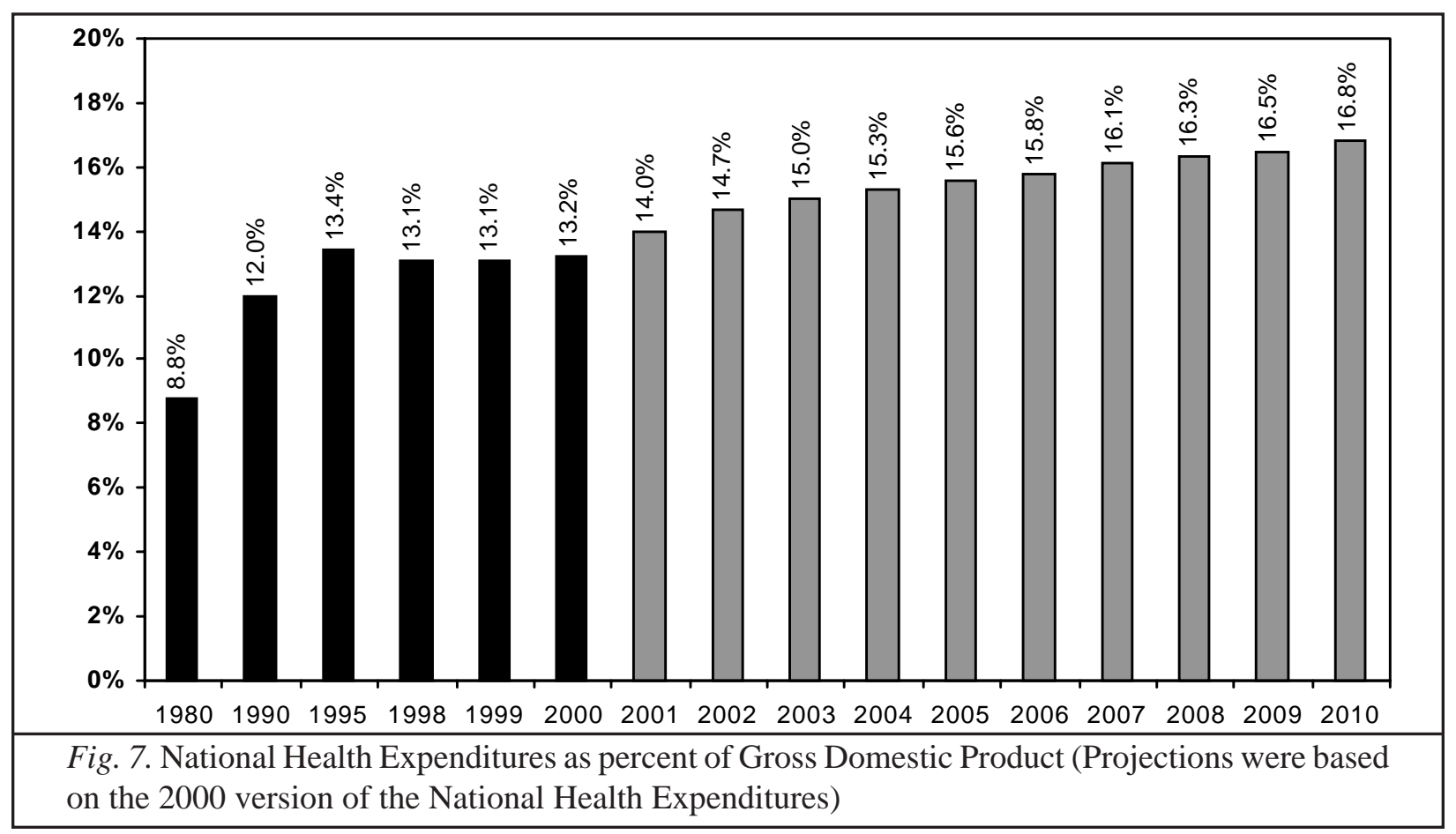




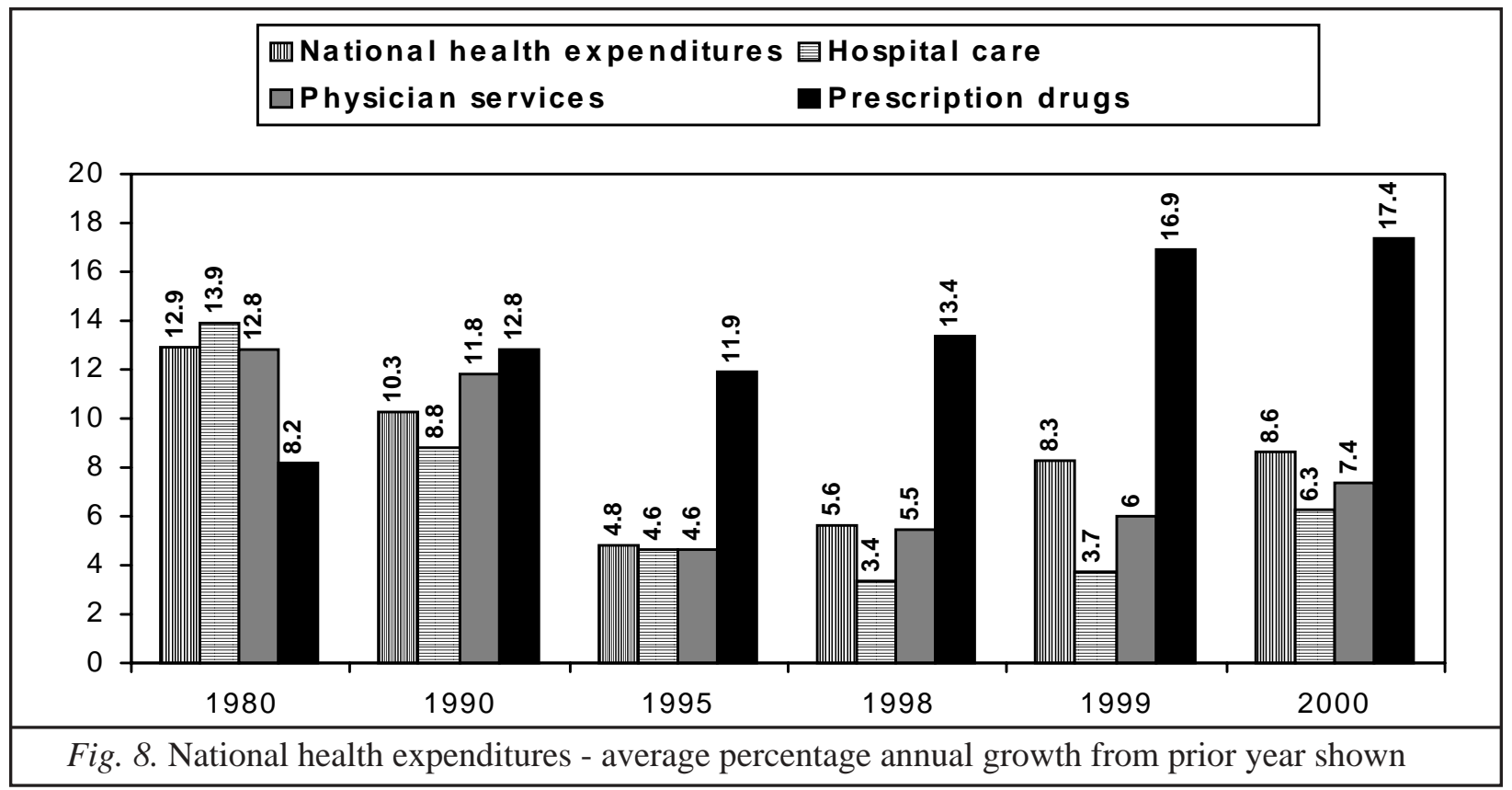

took birth to cut the costs with increasing participation in managed care organizations from 1982 through 2000 (Fig. 9). Even though there has been increase in enrollment in managed care organization participation, trends in HMO premiums are increasing (Fig. 10). Now there is a slowly growing realization spreading across the country that the problem of rapidly rising costs has returned as the most significant healthcare issue facing the nation (9). The trends in premiums suggest that we now are facing rates of increase that are equal to and soon to be greater than those of just a decade ago. In other words, we could say that we are right back where we used to be. Thus, it appears that we have lost the cost containment war, along with quality and access. There are several culprits and co-conspirators in the complicated world of healthcare for loss of cost containment.

\section{ROLE OF DOCUMENTATION}

Documentation is the cornerstone of the quality of patient care in medicine. While documentation is extremely important for billing and coding, its primary purpose is to assist healthcare professionals in providing appropriate services to patients. Thus, the documentation in each of the physician's office medical records, hospital settings, or ambulatory surgery centers, and rehabilitation centers and other settings must be accurate, complete, and reflect all of the services billed for each particular patient encounter. Accurate and complete documentation of the service is part and parcel of a solid compliance program and is certainly a necessity for delivery of quality care.

The medical record is the primary informational source for all services billed on behalf of the patient. Thus, the medical record must fully substantiate all types of services provided. The patient's medical record is an assemblage of information gathered and recorded pertaining to patient care. Appropriate documentation is fast becoming the only reliable assurance that providers can count on to provide appropriate patient care, to receive appropriate third party reimbursement, and finally, to retain a measure of protection against federal, state, and other payor auditors in their search for provider fraud and abuse. The accurate assignment and reporting of CPT and ICD-9-CM codes no longer guarantees payment, nor does the submission of "clean" claims. With the pre- and post-payment third party payor screens that edit services ranging from office visits to surgical procedures, almost all the claims submitted by the

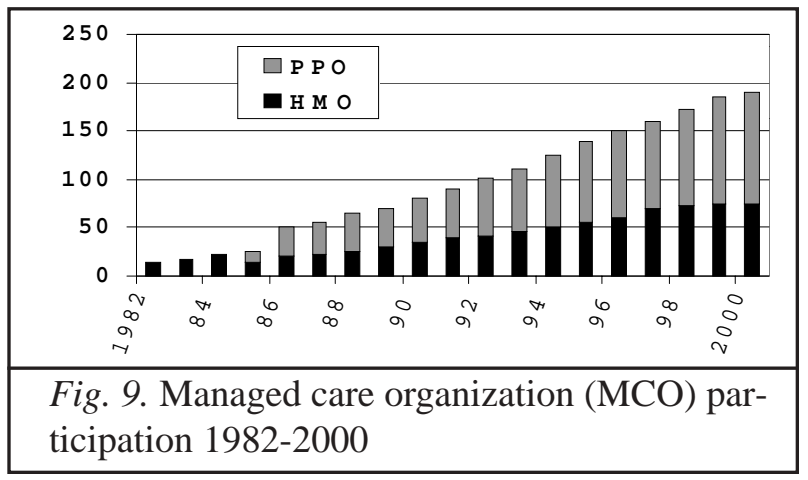




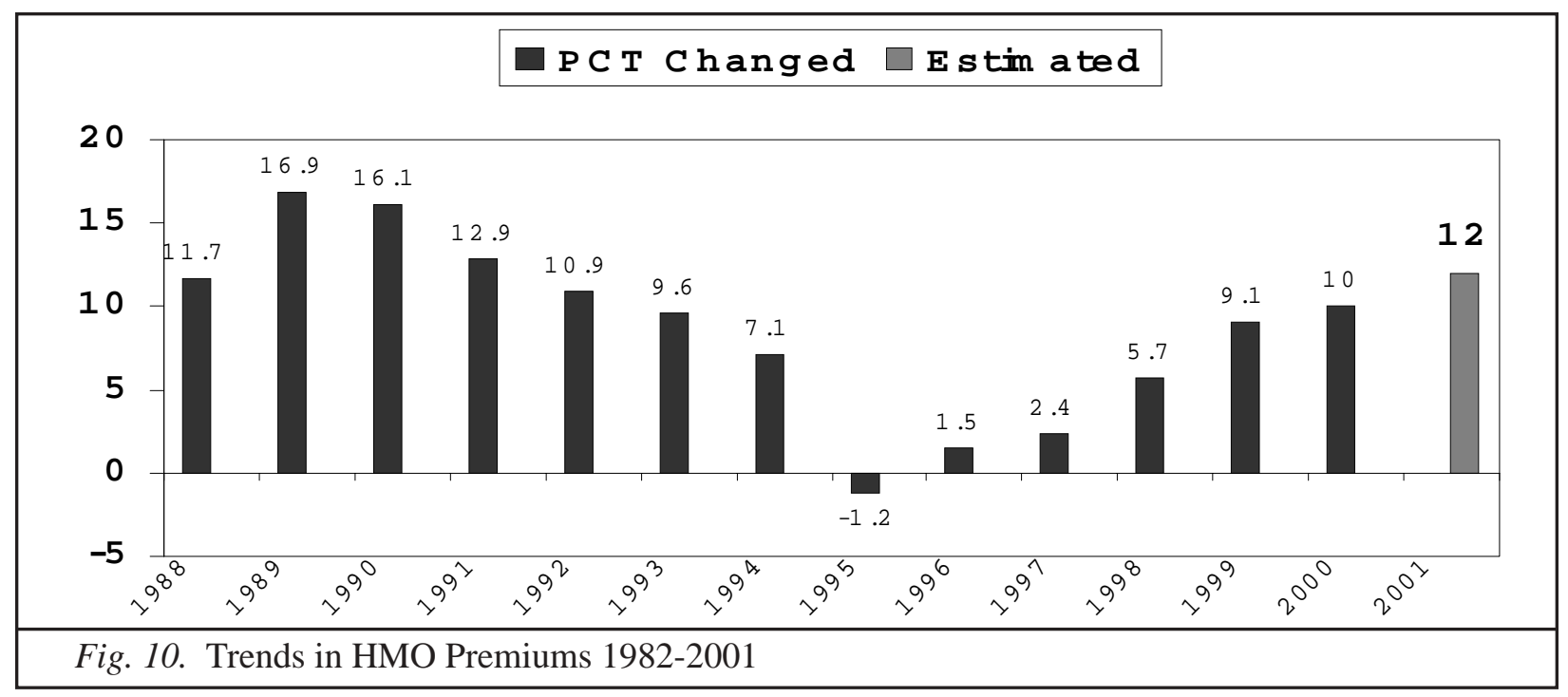

practitioner is potentially subject to meticulous scrutiny. In addition, in many of the cases, copies of the medical record entries must be sent to the carrier or for a final reimbursement determination when such information is requested. Thus, interest in medical record documentation has acquired a new urgency as it pertains to the correct coding and billing of services. Growth in regulatory and compliance activity further requires that documentation provided by the physician is not only accurate, but also detailed and specific. Documentation has never before been under such scrutiny by so many.

The physicians have not been historically taught and are required to be experts in documentation, billing and coding, and for many years they retained their independence over the medical records as their own territory. However, modern times are different and the medical record is a powerful weapon which can be used not only in protection of the physician or provider, but also against them.

Centers for Medicare and Medicaid Services (CMS) mandates the availability of provider medical records for Medicare beneficiaries for review of services billed to the Medicare program. The Provider Reimbursement Manual, Section 2304.1, states in part that "examination of such records and documents is necessary to ascertain information pertinent to the determination of the proper amount of program payments due the provider." In fact, federal, state, third party payor, and managed care plans rely heavily on provider documentation when accessing the claims for various parameters. These include:

- Was the billed service actually rendered or provided to the patient?

- Was the level of service or extent of the service accurately reported?

- Was the service or procedure medically necessary?

- Was the claim sent to the correct primary insurers for the service or procedure performed?

Documentation includes not only the physician handwritten or typed notes, nurses handwritten or typed notes, and the results of various tests and reports of consultation, etc., but also includes patient questionnaires, problem summary sheets, and finally, in-office or hospital notes as appropriate, to appropriately substantiate a particular claim for a particular service.

\section{ELEMENTS OF DOCUMENTATION}

Medical documentation may be of several types. Certain critical documentation, such as clinical notes and other medical records are always maintained in the patient's medical record. However, various other forms of documentation, such as patient waivers and financial data, insurance information, and patient hardship data may be maintained outside of the patient's chart. Under HIPAA Privacy Regulations, two charts will be mandatory.

The typical information for interventional pain medicine medical chart may include:

- Patient demographic data

- Medical insurance card copy

- Patient's drivers license copy

- Patient guarantee and authorization forms 
- Initial evaluation

- Progress notes

- Summary sheet with problems and medication history

- Patient questionnaires

- Laboratory test results

- Radiographic evaluation results

- Results of various medical tests

- Medical records from other providers

- Facility notes

- Consultation reports

- Correspondence

- Advanced beneficiary notice

- Various other orders with prescriptions, etc.

Essentially the same information is maintained whether it is an electronic format or hard copy. Some forms such as medical information releases, third party payor requests, and insurance claim form copies may not be physically maintained in patient medical charts.

Documentation outside the patients' medical record in another format may include the following:

- Encounter forms or super bills or charge sheets

- Physician orders

- Prescription refill logs

- Records of laboratory tests orders

- Managed care referral forms

- Patient account records

- Copies of explanation of benefits

- Other records

However, in criminal investigation related to fraud and abuse, similar to a malpractice litigation, the definition of documentation is taken, at times out of context, and at times, much further than a patient's medical record and may include the following:

- Appointment schedules

- Surgery schedules

- Appointment calendars

- Work planners

- Travel logs and records

- Telephone message logs

- Various notes and internal memoranda, not intended for inclusion into the patient medical records and also not intended for external disclosure

\section{DOCUMENTATION STANDARDS}

The documentation of patient care in the medical records must be accurate, complete, and reflect all services that have been billed for the patient during each particular session. Each visit must meet medical necessity criteria and each claim should be stand-alone. The medical record is the primary source document for all services billed and not your super bill or charge sheet. Thus, we go to the old saying, "if you have not documented, you haven't performed the service" in the eyes of federal, state, third party payor and managed care organizations. Any medical service that is not properly documented in the medical record, was simply not provided. Even though the idiom, "if it is not documented, it is not done" has been said throughout the medical history and industry for centuries, its prominence and growth has been spectacular and it does not appear to disappear but also appears to grow even rapidly. Simple, yet extremely important standards of documentation are listed in Table 1.

\section{GOVERNMENT'S PERSPECTIVE}

CMS has published many, many guidelines, instructions for providers and answers to providers-submitted questions that pertained to the recording of the patient-related information, both inside and outside of the medical record. The federal government does consider the patient medical record the primary source or original document for all patient healthcare information, as well as for services provided, whether the record is retained by a physician, independent nurse practitioner, psychiatrist, psychologist, physical therapist, ambulatory surgery center, rehab facility, or a hospital, or any other recognized provider of healthcare services. Under HIPAA of 1996, the federal government has been charged to conduct investigations, audits, evaluations, and inspections relating to the delivery of and "payment for healthcare in the United States." However, this charge is not limited to federal programs, such as Medicare and/or healthcare programs that are wholly or partially subsidized by federal funds, such as Medicaid, but, this act covers all healthcare benefits programs in the United States, whether public or private.

\section{DOCUMENTATION PROCESS}

Who is responsible for documentation? It is an important question and frequently discussed issue in offices on a daily basis. A multitude of personnel associated with a practice or a facility are responsible; however, we believe that the buck stops with the physician or the provider. Thus, not only the physicians but also other treating providers such as physician assistants, nurse practitioners, and clinical nurse specialists must take responsibility in documenta- 
tion for each and every patient encounter. Further, nurses and medical assistants who obtain patient histories and vital signs, administer injections and otherwise provide certain restricted services, must also likewise document and make clinical entries. Physical therapists, psychologists and other ancillary providers also need to complete specific medical treatment forms for the purpose of documentation of their services and findings are documented similar to physicians. Due to the fact that the patient medical record is considered not only a medical document, but also a legal document, authorization for making entries into the records should be limited by appropriate policy establishment. This will not only avoid entries by some personnel, which may go unnoticed by the provider, but also avoid unnecessary compromising, comments or situations.

There is tremendous variation in documentation standards among payors. Further, the variation is not just among the carriers but among individual carriers themselves with regional policies. Even Medicare carriers, which we believe must be consistent as they are all under Medicare administration, continued published varying documentation policies. This also applies to large health insurance companies such as Aetna, Blue Cross and Blue Shield, and United Health Care. To always meet the entire documentation criteria one should use a checklist and cover all aspects. Thus, a patient record:
- Support the medical necessity of the service performed,

- Provide clear description of the procedure or service including technique and end results,

- Should make it clear that the procedure was performed by the reporting or billing physician,

- Document appropriate and specific diagnosis code as, ICD-9 CM, diagnosis code,

- Provide documentation of indications and medical necessity, which may be reviewed by payors at any time,

- Must document specific regulations governing procedures performed in chronic pain management by many carriers, and

- Follow correct coding initiatives, and Local Medicare Review Policies with the limitations, which become part of documentation.

\section{OTHER ISSUES OF DOCUMENTATION}

Documentation is not only important for patient records, billing and coding, but also is extremely important in various other issues, such as employee training, employee warnings, contracts with various outside agencies, insurance correspondence, OSHA, billing and coding, as well as HIPAA complaints programs. Thus, documentation is the proof of each and every activity a practitioner performs in practice.

Table 1. Illustration of documentation standards

1. Medical records must be legible
2. All entries must be dated with month, day, and year
3. Every page in the chart should be patient-identified
4. Medical records should always be documented in permanent ink (not with pencil)
5. Incorrect entries should be crossed out with a single line with rewriting of the correct entry
6. Corrections should be dated and signed
7. All additions are dated, signed, and are clear
8. The credibility of notes written more than 24 to 48 hours after the care was rendered
9. Always provide sufficient information with samples and prescriptions
10. Document all health risk factors, including allergies and adverse reactions to medications, foods or
11. Summary sheet should have identifying information, height, weight, medication list, previous surger-
12. All telephone calls must be documented
13. Medical necessity for all diagnostic services or tests
14. Medical necessity for all procedures and interventions
15. Documentation of follow up treatment dates for coordination of services and services based on time,
16. All documents contained inside the chart should belong to that particular patient




\section{CONCLUSION}

Medical documentation is created to establish and maintain an accurate and enduring record of patient encounters with healthcare professionals and services. Thus, medical documentation can range from the smallest note, to a detailed, comprehensive evaluation. Documentation is an important part of interventional pain medicine for appropriate coding and billing and to also prove medical necessity and protect against fraud and abuse investigations. Additional benefits include protection against liability and also assist in providing quality patient care. Thus, documentation of interventional pain procedures throughout patient encounters and subsequent billing and coding are of crucial importance, not only in complying with the regulations, but also for good patient care. All interventional pain providers should realize that there is heightened emphasis on the description and definition of what the physician does for and to the patient in the United States as never before. Compliance with laws and regulations encompassing documentation, medical records, coding, billing, collections, contracts, auditing, and other areas are also of crucial importance in today's interventional pain physician.

\section{REFERENCES}

1. Feldman RD (ed). American Health Care. The Independent Institute, Transaction Publishers, New Brunswick, 2000.
2. Pauly MV. Foreword. In Feldman RD (ed). American Health Care. The Independent Institute, Transaction Publishers, New Brunswick, 2000 pp ix-xi.

3. Stigler GJ. The theory of economic regulation. Bell J Economics 1971; 2:3-21.

4. Feldman RD. Introduction. In Feldman RD (ed). American Health Care. The Independent Institute, Transaction Publishers, New Brunswick, 2000, pp 1-12.

5. Twight C. Medicare's Progency: The 1996 Health Care Legislation. In Feldman RD (ed). American Health Care. The Independent Institute, Transaction Publishers, New Brunswick, 2000, pp 87-118.

6. RAJ PP, Johnston M. Organization and function of the nerve block facility. In RAJ PP, Abrams BM, Benzon HT.(eds) Practical Management of Pain, ed. 3, Mosby, St. Louis, 2001; pp 545-556.

7. Hamowy R. The Genesis and Development of Medicare. In Feldman RD (ed). American Health Care. The Independent Institute, Transaction Publishers, New Brunswick, 2000, pp 15-85.

8. Henry FP. Theodore Roosevelt, Harcourt Brace, New York, 1956, pp 396-397.

9. Hurley R, Rawlings RB. Who lost cost containment? A roster for recrimination. Managed Care Quarterly 2001; 9:23-32. 